\title{
Fear induced neuronal alterations in a genetic model of depression: an fMRI study on awake animals
}

\author{
Wei Huanga ${ }^{\mathrm{a}}$, Meghan E. Heffernan ${ }^{\mathrm{a}}$, Zhixin $\mathrm{Li}^{\mathrm{b}}$, Nanyin Zhang ${ }^{\mathrm{a}}$, David H. Overstreet ${ }^{\mathrm{c}}$, and \\ Jean A. King a, \\ ${ }^{a}$ Center for Comparative Neurolmaging, University of Massachusetts Medical School, 55 Lake \\ Avenue North, Worcester, MA 01605 \\ ${ }^{b}$ Dept. of Biophysics, Medical College of Wisconsin, 8701 W. Watertown Plank Rd, Milwaukee, \\ WI 53226
}

'Bowles Center for Alcohol Studies, University of North Carolina at Chapel Hill School of Medicine, 7178 Thurston Bowles Building Chapel Hill, NC 27599

\begin{abstract}
Previous human imaging studies used facial stimuli to explore the potential association between depression and fear. This study aimed at investigating brain alterations in a rodent model of depression when innate fear was induced in the form of the predator odor trimethylthiazoline (TMT). Flinders sensitive line rats (FSL), a genetic animal model of depression, and their control counterpart Flinders resistant line (FRL), were used in this functional magnetic resonance imaging (fMRI) assessment. Compared to FRL, FSL rats exhibited greater BOLD activation in the cortical amygdala and hypoactivation in the prefrontal cortex in response to TMT, suggesting corticoamygdalar dysfunction in the depressed strain. In addition, the hyperactivation in the insular cortex in FSL rats may be the basis for enhanced neuronal responses to fear and aversion in depression. These results are evidence for the value of translational models of depression in expanding understanding of the neural circuitries sub-serving common human co-morbidities like depression and fear.
\end{abstract}

\section{Keywords}

fMRI; Depression; Fear

\section{INTRODUCTION}

Depression is a devastating disorder with estimates of $12 \%$ to $17 \%$ of the population experiencing at least one episode in a lifetime $[14,19]$. Neuroimaging studies demonstrated depressed patients exhibit amygdala hyperactivity $[18,26]$ and dorsal lateral prefrontal cortex (DLPFC) hypoactivity in response to negative emotional facial stimuli [2,6,34]. Patients recovered from depression showed an increased response to fearful facial stimuli in

\footnotetext{
(c) 2010 Elsevier Ireland Ltd. All rights reserved.

"Corresponding Author: Jean A. King, PhD., Professor and Director, Center for Comparative NeuroImaging, University of Massachusetts Medical School, 303 Belmont St, Worcester, MA 01604, Phone: (508)856-4979, Jean.Kingl@ umassmed.edu .

Publisher's Disclaimer: This is a PDF file of an unedited manuscript that has been accepted for publication. As a service to our customers we are providing this early version of the manuscript. The manuscript will undergo copyediting, typesetting, and review of the resulting proof before it is published in its final citable form. Please note that during the production process errors may be discovered which could affect the content, and all legal disclaimers that apply to the journal pertain.
} 
the DLPFC [6,37]. This neuronal link between depression and fear processing is well supported by the high prevalence of depression in combination with other mental health disorders such as selective fears, phobias and anxiety disorders. Since human imaging studies generally involve looking at fearful faces, the exploration of innate fear processing in an animal model may facilitate better understanding of the influence of depression upon more instinctual fear response.

A very useful paradigm to study innate fear in rodents is the utilization of a predator odor, often elicited by the odor of cats $[15,45]$ or foxes $[5,49,60]$. For the latter effect, a synthetic compound trimethylthiazoline (TMT) isolated from fox feces, has proven successful in producing fear-related responses in rats [44], including freezing, avoidance, increased defensive behaviors and stress hormone release $[10,21,50]$.

As a translational model to human depression studies, two genetically linked strains of rats were utilized. The Flinders sensitive line rat (FSL) is a well validated genetic animal model of depression [13,22,23], exhibiting a number of behavioral [12,24,48] and neurochemical $[1,28,42]$ similarities to depression in humans. The Flinders resistant line (FRL), was developed as a control counterpart for the FSL strain [57]. These two lines have maintained their differential sensitivities over numerous generations [12], supporting validity construct mechanisms including good face and predictive validity [7].

In this study we used functional magnetic resonance imaging (fMRI) to examine brain response to innate fear elicited by TMT in an FSL rat model of depression. This study will explore the brain network underlying the direct fear response in an animal model of depression. We hypothesize that the fearful stimulus will elicit differential activation in selected brain areas within the brain circuitry subserving emotional regulation in depressed lines compared to controls.

\section{MATERIALS AND METHODS}

\section{Animals}

Male FSL ( $\mathrm{n}=8)$ and FRL $(\mathrm{n}=8)$ rats $(350-400 \mathrm{~g})$ were bred at the University of North Carolina, Chapel Hill. After shipment, all rats were housed in pairs and were given at least 2 weeks to adjust to the new environment. The housing environment was maintained at $22-24^{\circ} \mathrm{C}$ with a 12 hour light/dark schedule (lights on at 06:00 and off at 18:00). Food and water were provided ad libitum. All rats were acquired and cared for in accordance with the guidelines published in the NIH Guide for the Care and Use of Laboratory Animals.

\section{Preparation and Acclimation for Imaging}

In order to scan fully conscious rats in a magnetic resonance imaging (MRI) scanner, the rats must be restrained [29]. To reduce physiologic stress and motion artifact during imaging, the animals were acclimated to the restraint and imaging procedures before imaging for eight consecutive days using a previously validated acclimation procedure [51].

fMRI

All images were acquired using a Bruker $4.7 T / 40 \mathrm{~cm}$ horizontal magnet and a $20 \mathrm{Gauss} / \mathrm{cm}$ magnetic field gradient insert (inner diameter $=12 \mathrm{~cm}$, Bruker, Billerica, MA U.S.A). High resolution multi-slice anatomical images were obtained using rapid acquisition relaxation enhanced sequence (RARE) with relaxation time $T R=2.0 \mathrm{~s}$, echo time $\mathrm{TE}=12 \mathrm{~ms}$, resolution matrix $=256 \times 256$, field of view $(F O V)=30 \mathrm{~mm} \times 30 \mathrm{~mm}, 121.2-\mathrm{mm}$ slices. Two subsequent functional scans were performed using echo-planar imaging sequence (EPI) at a resolution of $64 \times 64$ with the same FOV and slice thickness. TR=2.0s, TE $=55 \mathrm{~ms}$, total acquisition time 
for each EPI scan was about 6 minutes. The first EPI scan had a 2 minute baseline period when fresh air was presented, followed by 4 minutes of neutral scent (lemon). In the second EPI, lemon was replaced by TMT.

\section{Image Processing and Data Analysis}

All images were examined for artifacts and motion using Stimulate [58] and processed using the in-house developed software MIVA (Medial Image Visualization and Analysis, (http://ccni.wpi.edu ). Motion was corrected using SPM8 [41]. On rare occasions, EPIs with motion bigger than $1 / 3$ of the pixel size $(\sim 0.15 \mathrm{~mm})$ were excluded.

Each rat within group was aligned to a standard and thereafter to a fully segmented digital rat brain atlas that delineates 12 major anatomical regions and more than 70 subregions that are involved in different neural activities, based on 2D atlas textbooks [8,52]. The anatomy volumes were aligned to the brain atlas volume using interactive affine registration [55]. All transformed pixel locations of the anatomy images were tagged with the segmented atlas major and sub regions creating a fully segmented map of each subject.

Structural regions of interest (ROIs) were predetermined based on previous studies with TMT $[21,30]$ and other regions commonly cited to be involved in depression and fear response. Results particularly presented the olfactory bulb, prefrontal cortex (PFC), insular cortex, bed nucleus of the stria terminalis (BNST), amygdala and thalamus.

EPIs were analyzed following the above preprocessing. The first few scans were discarded to eliminate T1 effects. 55 scans before and 100 scans after the presentation of TMT were specified as the control and stimulation windows, respectively. Student t-tests were performed on each subject to determine pixel signal activity, using a 99\% confidence level, two-tailed distribution and heteroscedastic variance assumptions. A statistical composite map in the standard space was created for each group with the average blood-oxygenationlevel dependent (BOLD) activation on a pixel-by-pixel basis. In order to estimate regional differences, one-way ANOVA was performed between groups for each brain region, with $\mathrm{p}<0.05$ as level of significance (degrees of freedom $\mathrm{df}=14$ ).

\section{RESULTS}

Neural responses to both lemon scent and TMT were examined in FRL and FSL animals. Figures 1 and 2A compare regional BOLD changes of both groups in their response to lemon and TMT relative to baseline (fresh air). In the olfactory area (namely the olfactory bulb), there was no significant difference between the two groups in response to either of the two odors, neither was there a difference between the two odors.

In other selected brain areas associated with fear, lemon did not induce significantly different BOLD change between the two groups (Figure 1); whereas when exposed to TMT, FSL showed stronger activations in the cortical nucleus of the amygdala $(\mathrm{F}=5.0, \mathrm{p}=0.045)$ and insular cortex $(\mathrm{F}=17.2, \mathrm{p}=0.002)$, compared to FRL. In the PFC, less BOLD activation was observed in FSL ( $\mathrm{F}=6.024, \mathrm{p}=0.03$ ). No significant difference was observed in the BNST and thalamus between the two groups (Figure 2A). Representative regional time courses are shown in Figure 2B and 2C.

Figure 3 depicts a composite map of TMT odor-induced BOLD activation of positive BOLD signal response across the brain. The activated voxels (based on a t-test, thresholded at $\mathrm{p}<0.05)$ are overlaid onto the anatomy atlas. 


\section{DISCUSSION}

This study was performed to assess the impact of depression-like phenotype on responding to an innate fear-evoking stimulus [2]. Prior studies have demonstrated increases in fearrelated behavior of the FSL rats compared to their control counterparts [17,32], supporting our functional imaging results of differential brain activation patterns between the two lines when processing fear. BOLD activation in the olfactory system when exposed to either lemon or TMT was similar between groups, indicating the differential neural activity found in brain areas between the two phenotypic groups is not induced by olfactory deficits. Similar BOLD activation in response to the neutral scent lemon ensures any difference found in TMT exposure is related to fear induced by this particular odor. Further, any additional stress associated with acclimation and restraint was constant between baseline and stimulus periods. Since BOLD changes were calculated as a difference between baseline and stimulus periods, this potential alteration would have been taken into account.

Our results strongly support three critical brain regions, namely the cortical amygdala, PFC and insular cortex in processing fear-related stimulus in the animal model of depression versus their control counterparts. First, hyperactivity in the cortical nucleus of the amygdala in response to TMT in FSL animals is consistent with human findings that the amygdala plays an important role in fear response [20], especially under negative emotional states like depression. While most human studies focus on the entire amygdala (mainly the central nucleus) $[2,34,35]$, others have reported the role of basolateral amygdala [18] as essential to fear processing. Although prior studies have linked the cortical nucleus of amygdala to smell and pheromone-processing [4] others reported that the posterior cortical nucleus modulates memory processing [54], to our knowledge the role of the cortical amygdala in depression related fear processing is not well established. The current observed exaggerated activation in this region suggests the cortical nucleus of the amygdala is a critical area in depressed subjects processing innate fear stimuli.

Decreased PFC activity in response to fear aligns well with previous work in the FSL animal model. Using the FSL strain and Sprague-Dawley (SD) rats as controls, Yadid et al. assessed the effects of stress on dopamine release from the PFC [40]. Their findings demonstrated diminished dopamine release in response to stress in the FSL compared to controls. The observed hypoactivity of the PFC in the FSL rats after the application of fearful stimuli may be due to alterations in dopamine [16,31,34], norepinephrine [53] and/or the serotonin[3,59].

This study also found evidence of enhanced activation in the insular cortex in response to fear induction in FSL animals. Although both gray matter reduction [11] and hypoactivity in the insular cortex have been documented in depression [56], the enhanced activation in the current study may be due to complex role of the insular cortex in environmental monitoring and negative emotional processing [39,43,61]. Given the emotional regulatory influence of the insular cortex [9,25] particularly its known function (in tandem with the amygdala) in contributing to the integration of emotional salience [43,46,47], the observed increased activation in the insular is not unexpected.

Our results in depressed subjects demonstrate a dysfunctional relationship in the processing of information between the PFC and amygdala in an animal model [34]. Since the PFC acts as a primary cortical control of the limbic system while the amygdala functions as a regulatory structure for the processing of emotional experiences [38], we speculate that a contrast of hyper- and hypoactivity seen in the amygdala and PFC respectively may be a critical circuitry sub-serving the exaggerated emotional responses often observed in depressed subjects. This proposal of a dual regulatory capacity of the cortico-limbic loop is supported by previous studies performed in a selectively bred genetic animal model for high 
$(\mathrm{HAB})$ and low $(\mathrm{LAB})$ anxiety-related behavior $[27,33]$. However, the HAB rodents are genetically susceptible to high anxiety with comorbidity of depression [36]; whereas the FSL line is selectively bred to exhibit only depression-like similarities. The aim of this study was to investigate the neural networks of fear processing in depression, rather than the networks supporting the coexistence of the phenotypically disparate mood states of depression and anxiety. Nonetheless, the similarities in finding of amygdala-prefrontal cortex dysregulation in both lines, strengthens the argument of a dysfunctional mechanism of fear processing in subjects with a mood disorder.

In conclusion, our results suggest that depression influences the neural response to innate fear in an animal model of depression. The pre-existing negative emotional state of depression supported enhanced cortical amygdala and insular reactivity, as well as a diminished PFC activation. These results also promote the utilization of translational models of depression to expand our understanding of the neural circuitries sub-serving common human co-morbidities like depression and fear/anxiety.

\section{Highlights}

- Depression influences the neural response to innate fear

- Depression associated with enhanced amygdala activity during fear

- Depression associated with diminished prefrontal activation during fear

- Animal models can expand understanding of co-morbidity

\section{Acknowledgments}

This publication was made possible by the NIH Grant Number 1RO1 MH067096. Its contents are solely the responsibility of the authors and do not necessarily represent the official views of the NIH.

\section{REFERENCES}

[1]. Caberlotto L, Jimenez P, Overstreet DH, Hurd YL, Mathe AA, Fuxe K. Alterations in neuropeptide $\mathrm{Y}$ levels and Y1 binding sites in the Flinders Sensitive Line rats, a genetic animal model of depression. Neurosci Lett. 1999; 265:191-4. [PubMed: 10327163]

[2]. Fales CL, Barch DM, Rundle MM, Mintun MA, Snyder AZ, Cohen JD, Mathews J, Sheline YI. Altered emotional interference processing in affective and cognitive-control brain circuitry in major depression. Biol Psychiatry. 2008; 63:377-84. [PubMed: 17719567]

[3]. Patterson ZR, Ducharme R, Anisman H, Abizaid A. Altered metabolic and neurochemical responses to chronic unpredictable stressors in ghrelin receptor-deficient mice. Eur J Neurosci. 2010; 32:632-9. [PubMed: 20597975]

[4]. Best B. The amygdala and the emotions. 2004

[5]. Rosen JB, Pagani JH, Rolla KL, Davis C. Analysis of behavioral constraints and the neuroanatomy of fear to the predator odor trimethylthiazoline: a model for animal phobias. Neurosci Biobehav Rev. 2008; 32:1267-76. [PubMed: 18619675]

[6]. Fales CL, Barch DM, Rundle MM, Mintun MA, Mathews J, Snyder AZ, Sheline YI. Antidepressant treatment normalizes hypoactivity in dorsolateral prefrontal cortex during emotional interference processing in major depression. J Affect Disord. 2009; 112:206-11. [PubMed: 18559283]

[7]. Licht CL, Marcussen AB, Wegener G, Overstreet DH, Aznar S, Knudsen GM. The brain 5-HT4 receptor binding is down-regulated in the Flinders Sensitive Line depression model and in response to paroxetine administration. J Neurochem. 2009; 109:1363-74. [PubMed: 19476548]

[8]. Swanson, LW. Brain Maps: structure of the rat brain. 2nd edition. Elsevier; the Netherlands: 1998. 
[9]. Buchel C, Morris J, Dolan RJ, Friston KJ. Brain systems mediating aversive conditioning: an event-related fMRI study. Neuron. 1998; 20:947-57. [PubMed: 9620699]

[10]. Perrot-Sinal TS, Ossenkopp KP, Kavaliers M. Brief predator odour exposure activates the HPA axis independent of locomotor changes. Neuroreport. 1999; 10:775-80. [PubMed: 10208547]

[11]. Peng J, Liu J, Nie B, Li Y, Shan B, Wang G, Li K. Cerebral and cerebellar gray matter reduction in first-episode patients with major depressive disorder: A voxel-based morphometry study. Eur J Radiol. 2010

[12]. Overstreet DH, Daws LC, Schiller GD, Orbach J, Janowsky DS. Cholinergic/serotonergic interactions in hypothermia: implications for rat models of depression. Pharmacol Biochem Behav. 1998; 59:777-85. [PubMed: 9586831]

[13]. Overstreet DH. Commentary: a behavioral, psychopharmacological, and neurochemical update on the Flinders Sensitive Line rat, a potential genetic animal model of depression. Behav Genet. 1991; 21:67-74. [PubMed: 1673333]

[14]. Kessler RC, Nelson CB, McGonagle KA, Liu J, Swartz M, Blazer DG. Comorbidity of DSM-III$\mathrm{R}$ major depressive disorder in the general population: results from the US National Comorbidity Survey. Br J Psychiatry Suppl. 1996:17-30. [PubMed: 8864145]

[15]. Dielenberg RA, McGregor IS. Defensive behavior in rats towards predatory odors: a review. Neurosci Biobehav Rev. 2001; 25:597-609. [PubMed: 11801285]

[16]. Bermpohl F, Fregni F, Boggio PS, Thut G, Northoff G, Otachi PT, Rigonatti SP, Marcolin MA, Pascual-Leone A. Effect of low-frequency transcranial magnetic stimulation on an affective go/ no-go task in patients with major depression: role of stimulation site and depression severity. Psychiatry Res. 2006; 141:1-13. [PubMed: 16352348]

[17]. Pucilowski O, Overstreet DH, Rezvani AH, Janowsky DS. Effect of verapamil on submissive behavior in genetically bred hypercholinergic rats in a water competition test. Eur J Pharmacol. 1990; 187:507-11. [PubMed: 2073924]

[18]. Wallace TL, Stellitano KE, Neve RL, Duman RS. Effects of cyclic adenosine monophosphate response element binding protein overexpression in the basolateral amygdala on behavioral models of depression and anxiety. Biol Psychiatry. 2004; 56:151-60. [PubMed: 15271583]

[19]. Kessler RC, Berglund P, Demler O, Jin R, Koretz D, Merikangas KR, Rush AJ, Walters EE, Wang PS. The epidemiology of major depressive disorder: results from the National Comorbidity Survey Replication (NCS-R). Jama. 2003; 289:3095-105. [PubMed: 12813115]

[20]. LeDoux J. Fear and the brain: where have we been, and where are we going? Biol Psychiatry. 1998; 44:1229-38. [PubMed: 9861466]

[21]. Chen W, Shields J, Huang W, King JA. Female fear: influence of estrus cycle on behavioral response and neuronal activation. Behav Brain Res. 2009; 201:8-13. [PubMed: 19428610]

[22]. Overstreet DH, Friedman E, Mathe AA, Yadid G. The Flinders Sensitive Line rat: a selectively bred putative animal model of depression. Neurosci Biobehav Rev. 2005; 29:739-59. [PubMed: 15925699]

[23]. Overstreet DH. The Flinders sensitive line rats: a genetic animal model of depression. Neurosci Biobehav Rev. 1993; 17:51-68. [PubMed: 8455816]

[24]. Shiromani PJ, Overstreet D. Free-running period of circadian rhythms is shorter in rats with a genetically upregulated central cholinergic system. Biol Psychiatry. 1994; 36:622-6. [PubMed: 7833429]

[25]. Phan KL, Wager T, Taylor SF, Liberzon I. Functional neuroanatomy of emotion: a meta-analysis of emotion activation studies in PET and fMRI. Neuroimage. 2002; 16:331-48. [PubMed: 12030820]

[26]. Whalen PJ, Shin LM, Somerville LH, McLean AA, Kim H. Functional neuroimaging studies of the amygdala in depression. Semin Clin Neuropsychiatry. 2002; 7:234-42. [PubMed: 12382206]

[27]. Frank E, Salchner P, Aldag JM, Salome N, Singewald N, Landgraf R, Wigger A. Genetic predisposition to anxiety-related behavior determines coping style, neuroendocrine responses, and neuronal activation during social defeat. Behav Neurosci. 2006; 120:60-71. [PubMed: 16492117] 
[28]. Nishi K, Kanemaru K, Diksic M. A genetic rat model of depression, Flinders sensitive line, has a lower density of 5-HT(1A) receptors, but a higher density of 5-HT(1B) receptors, compared to control rats. Neurochem Int. 2009; 54:299-307. [PubMed: 19121358]

[29]. Lahti KM, Ferris CF, Li F, Sotak CH, King JA. Imaging brain activity in conscious animals using functional MRI. J Neurosci Methods. 1998; 82:75-83. [PubMed: 10223517]

[30]. Chen W, Tenney J, Kulkarni P, King JA. Imaging unconditioned fear response with manganeseenhanced MRI (MEMRI). Neuroimage. 2007; 37:221-9. [PubMed: 17570684]

[31]. Grimm S, Beck J, Schuepbach D, Hell D, Boesiger P, Bermpohl F, Niehaus L, Boeker H, Northoff G. Imbalance between left and right dorsolateral prefrontal cortex in major depression is linked to negative emotional judgment: an fMRI study in severe major depressive disorder. Biol Psychiatry. 2008; 63:369-76. [PubMed: 17888408]

[32]. Overstreet DH, Rezvani AH, Janowsky DS. Impaired active avoidance responding in rats selectively bred for increased cholinergic function. Physiol Behav. 1990; 47:787-8. [PubMed: 2385654]

[33]. Muigg P, Hetzenauer A, Hauer G, Hauschild M, Gaburro S, Frank E, Landgraf R, Singewald N. Impaired extinction of learned fear in rats selectively bred for high anxiety--evidence of altered neuronal processing in prefrontal-amygdala pathways. Eur J Neurosci. 2008; 28:2299-309. [PubMed: 19019199]

[34]. Siegle GJ, Thompson W, Carter CS, Steinhauer SR, Thase ME. Increased amygdala and decreased dorsolateral prefrontal BOLD responses in unipolar depression: related and independent features. Biol Psychiatry. 2007; 61:198-209. [PubMed: 17027931]

[35]. Sheline YI, Barch DM, Donnelly JM, Ollinger JM, Snyder AZ, Mintun MA. Increased amygdala response to masked emotional faces in depressed subjects resolves with antidepressant treatment: an fMRI study. Biol Psychiatry. 2001; 50:651-8. [PubMed: 11704071]

[36]. Wiehager S, Beiderbeck DI, Gruber SH, El-Khoury A, Wamsteeker J, Neumann ID, Petersen A, Mathe AA. Increased levels of cocaine and amphetamine regulated transcript in two animal models of depression and anxiety. Neurobiol Dis. 2009; 34:375-80. [PubMed: 19254763]

[37]. Norbury R, Selvaraj S, Taylor MJ, Harmer C, Cowen PJ. Increased neural response to fear in patients recovered from depression: a 3T functional magnetic resonance imaging study. Psychol Med. 2009:1-8. [PubMed: 19335938]

[38]. Wiech K, Tracey I. The influence of negative emotions on pain: behavioral effects and neural mechanisms. Neuroimage. 2009; 47:987-94. [PubMed: 19481610]

[39]. Malhi GS, Lagopoulos J, Sachdev PS, Ivanovski B, Shnier R, Ketter T. Is a lack of disgust something to fear? A functional magnetic resonance imaging facial emotion recognition study in euthymic bipolar disorder patients. Bipolar Disord. 2007; 9:345-57. [PubMed: 17547581]

[40]. Yadid G, Overstreet DH, Zangen A. Limbic dopaminergic adaptation to a stressful stimulus in a rat model of depression. Brain Res. 2001; 896:43-7. [PubMed: 11277971]

[41]. Friston KJ, Williams S, Howard R, Frackowiak RS, Turner R. Movement-related effects in fMRI time-series. Magn Reson Med. 1996; 35:346-55. [PubMed: 8699946]

[42]. Friedman EM, Irwin MR, Overstreet DH. Natural and cellular immune responses in Flinders sensitive and resistant line rats. Neuropsychopharmacology. 1996; 15:314-22. [PubMed: 8873115]

[43]. Lee BT, Seok JH, Lee BC, Cho SW, Yoon BJ, Lee KU, Chae JH, Choi IG, Ham BJ. Neural correlates of affective processing in response to sad and angry facial stimuli in patients with major depressive disorder. Prog Neuropsychopharmacol Biol Psychiatry. 2008; 32:778-85. [PubMed: 18207298]

[44]. Rosen JB. The neurobiology of conditioned and unconditioned fear: a neurobehavioral system analysis of the amygdala. Behav Cogn Neurosci Rev. 2004; 3:23-41. [PubMed: 15191640]

[45]. Do Monte FH, Canteras NS, Fernandes D, Assreuy J, Carobrez AP. New perspectives on betaadrenergic mediation of innate and learned fear responses to predator odor. J Neurosci. 2008; 28:13296-302. [PubMed: 19052221]

[46]. McNish KA, Davis M. Olfactory bulbectomy enhances sensitization of the acoustic startle reflex produced by acute or repeated stress. Behav Neurosci. 1997; 111:80-91. [PubMed: 9109626] 
[47]. Kroon JA, Carobrez AP. Olfactory fear conditioning paradigm in rats: effects of midazolam, propranolol or scopolamine. Neurobiol Learn Mem. 2009; 91:32-40. [PubMed: 19010431]

[48]. Daws LC, Overstreet DH. Ontogeny of muscarinic cholinergic supersensitivity in the Flinders Sensitive Line rat. Pharmacol Biochem Behav. 1999; 62:367-80. [PubMed: 9972706]

[49]. Wallace KJ, Rosen JB. Predator odor as an unconditioned fear stimulus in rats: elicitation of freezing by trimethylthiazoline, a component of fox feces. Behav Neurosci. 2000; 114:912-22. [PubMed: 11085605]

[50]. Morrow BA, Redmond AJ, Roth RH, Elsworth JD. The predator odor, TMT, displays a unique, stress-like pattern of dopaminergic and endocrinological activation in the rat. Brain Res. 2000; 864:146-51. [PubMed: 10793199]

[51]. King JA, Garelick TS, Brevard ME, Chen W, Messenger TL, Duong TQ, Ferris CF. Procedure for minimizing stress for fMRI studies in conscious rats. J Neurosci Methods. 2005; 148:154-60. [PubMed: 15964078]

[52]. Paxinos, G.; Watson, C. The Rat Brain in stereotaxic coordinates. 4th edn.. Academic Press; 1998. p. 256fourth edition

[53]. Schatzberg AF, SJ. Recent studies on norepinephrine systems in mood disorders, Back to Psychopharmacology: The Fourth Generation of Progress. Raven Press Ltd; New York, NY: 1995. p. 911-920.

[54]. Pitkanen A, Pikkarainen M, Nurminen N, Ylinen A. Reciprocal connections between the amygdala and the hippocampal formation, perirhinal cortex, and postrhinal cortex in rat. A review. Ann N Y Acad Sci. 2000; 911:369-91. [PubMed: 10911886]

[55]. Zhang, J.; Sullivan, JM.; Wu, Z.; Huang, W.; Kinkar, S. Registration and visualization, a framework for multi-modality imaging registration and visualization; 8th US National Congress on Computational Mechanics; 2005;

[56]. Strigo IA, Matthews SC, Simmons AN. Right anterior insula hypoactivity during anticipation of homeostatic shifts in major depressive disorder. Psychosom Med. 2010; 72:316-23. [PubMed: 20100882]

[57]. Overstreet DH, Russell RW, Helps SC, Messenger M. Selective breeding for sensitivity to the anticholinesterase DFP. Psychopharmacology (Berl). 1979; 65:15-20. [PubMed: 116286]

[58]. Strupp JP. Stimulate: a GUI based fMRI analysis software package. Neuroimage. 1996; 3:S607.

[59]. Liston C, Miller MM, Goldwater DS, Radley JJ, Rocher AB, Hof PR, Morrison JH, McEwen BS. Stress-induced alterations in prefrontal cortical dendritic morphology predict selective impairments in perceptual attentional set-shifting. J Neurosci. 2006; 26:7870-4. [PubMed: 16870732]

[60]. Fendt M, Endres T, Apfelbach R. Temporary inactivation of the bed nucleus of the stria terminalis but not of the amygdala blocks freezing induced by trimethylthiazoline, a component of fox feces. J Neurosci. 2003; 23:23-8. [PubMed: 12514197]

[61]. Taylor KS, Seminowicz DA, Davis KD. Two systems of resting state connectivity between the insula and cingulate cortex. Hum Brain Mapp. 2009; 30:2731-45. [PubMed: 19072897] 


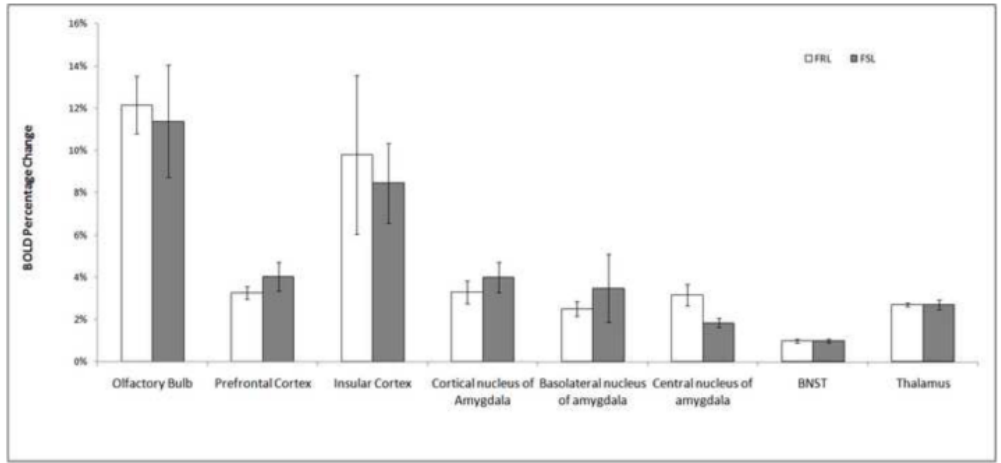

Figure 1.

Regional BOLD signal changes in FRL ( $\mathrm{n}=8)$ and FSL $(\mathrm{n}=8)$ rats in response to lemon, with errors of mean. Single factor ANOVA was performed to evaluate significance. No significant difference was shown between the two groups in their response to lemon. 


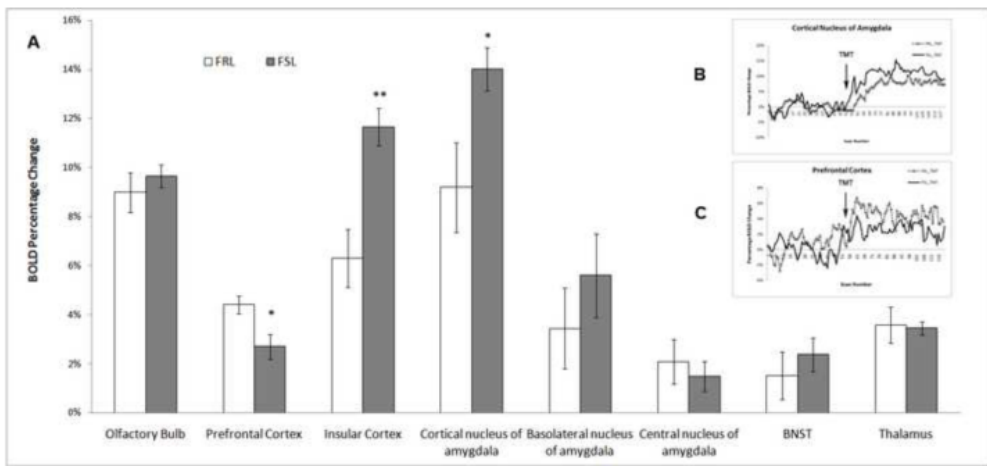

Figure 2.

(A) BOLD signal changes in brain areas of FRL $(n=8)$ and FSL $(n=8)$ rats in response to TMT odor, with errors of mean. Higher activation from the FSL group was found in cortical amygdala and insular cortex, and lower activation in the prefrontal cortex. *: p<0.05; **: $\mathrm{p}<0.02$. (B) Time course for the cortical nucleus of amygdala. (C) Time course for the prefrontal cortex. 


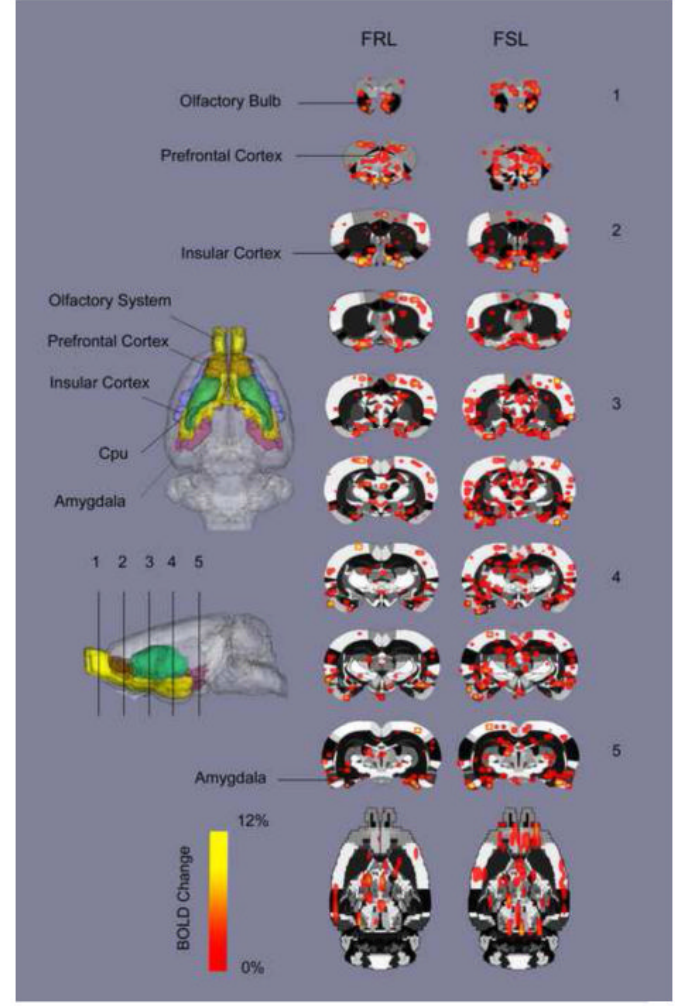

Figure 3.

TMT-elicited BOLD percent activation maps across the brain of FRL and FSL animals, overlaid on a fully segmented rat brain atlas. Each numbered slice is corresponding to the slices marked in the 3D atlas side view (based on a student t-test, thresholded at $\mathrm{p}<0.05$ ). 